\title{
NRF2 gene expression and DNA fragmentation markers as possible predictors of chronic smoking induced spermatozoa dysfunction in infertility with normal seminogram
}

\author{
Original \\ Ayman Z. Elsamanoudy ${ }^{1,4}$, Dalia Shaalan', Salwa M. Abo El-khair ${ }^{1}$, Mohammad \\ Article \\ A. Gaballah ${ }^{2}$, Ahmed F. State ${ }^{2}$, Ahmed M.N. Helaly \\ ${ }^{1}$ Medical Biochemistry and Molecular Biology, ${ }^{2}$ Dermatology, Andrology \& STDs, ${ }^{3}$ Forensic \\ Medicine and Clinical Toxicology Deparmtemt, Faculty of Medicine, Mansoura University, \\ El-Gomhoria St., Mansoura, Egypt, ${ }^{4}$ Clinical Biochemistry Department, Faculty of Medicine, \\ King Abdulaziz University, Saudia Arabia
}

\begin{abstract}
Introduction: Male factor is responsible for about half of infertility problems. However, the reasons for the decrease in male fertility are still broadly unclear. The mechanisms of how smoking may impact male fertility have not been established. However, with its influence on different semen parameters, it is regarded as a risk factor for infertility.

Aim: To investigate the effect of chronic smoking on spermatozoa NRF2 expression and DNA fragmentation in infertile men with apparently normal seminogram and to determine if NRF2 expression and DNA fragmentation markers could be possible predictors of the impact of chronic cigarette smoking on male fertility.

Methods: Semen samples were collected from 170 subjects; 65 nonsmokers (40 fertile and 25 infertile) and 105 smokers (25 fertile and 80 infertile). NRF2 gene expression, 8-OHdG and DNA fragmentation were assayed.

Results: There were significant increases in $8-\mathrm{OHdG}$ and \%DNA fragmentation with a significant decrease in NRF2 gene expression in infertile smokers. ROC curve analysis of spermatozoa NRF2 gene expression showed $95 \%$ sensitivity 93.3\% specificity at cutoff value $\leq 0.931(p<0.0001)$ differentiating infertile smokers from controls. Moreover, seminal 8 -OHdG assay shows $93.4 \%$ sensitivity, $89.2 \% \%$ specificity, at cutoff values $>19.33 \mathrm{pg} / \mathrm{ml}$ predicting the detrimental effect of smoking on spermatozoa DNA.

Conclusion: Chronic cigarette smoking may be a hidden causative mechanism of delayed fertility. Spermatozoa NRF2 gene expression and seminal 8-OHdG levels may serve as sensitive diagnostic indicators predicting smoking induced infertility. So, the presence of normal seminal parameters could not be an exclusion of potential effect of chronic smoking on male fertility.
\end{abstract}

Key Words: NRF2, DNA fragmentation, male infertility, smoking.

Received: 13 September 2017, Accepted: 10 November 2017

Corresponding Author: Mohammad Gaballah, Tel.: 00201118612527, E-mail: mohali212@yahoo.com

ISSN: 2090-6048, September 2017, Vol. 7, No. 4

\section{INTRODUCTION}

Infertility affects $10-15 \%$ of all couples worldwide ${ }^{[1]}$ and male factor is responsible for about half of infertility problems ${ }^{[2]}$. However, the reasons for the decrease in male fertility are still broadly unclear.

Cigarette smoke can induce oxidative damage of the sperms through production of reactive oxygen species (ROS) that may exceed the antioxidant capacity of seminal plasma $^{[3]}$. The mechanisms of how smoking may impact male fertility have not been established ${ }^{[4]}$. However, with its influence on different semen parameters, it is regarded as a risk factor for infertility ${ }^{[5]}$.

Nuclear factor erythroid 2 - related factor 2 (NRF2) is a member of Cap-N-Collar family transcription factors. It regulates transcription of genes that have promoters containing antioxidant response elements (AREs). The signaling pathway of NRF2 - ARE plays a key role in the response to oxidative stress through the induction of cytoprotective and antioxidant enzymes ${ }^{[6]}$. This pathway plays crucial roles in cellular defense against oxidative 
stress during the processes of spermatogenesis and fertilization $^{[7]}$.

The severe oxidative DNA damage may prevent oocyte fertilization, and could be a cause of infertility. Analysis of sperm DNA fragmentation after capacitation detects tobacco detrimental effect that alters the sperm swim-up selection process ${ }^{[8]}$. Some researchers did not find any association between smoking and DNA fragmentation. Yet, a clear negative effect was observed through disturbance of plasma membrane phospholipids asymmetry ${ }^{[9]}$. Our hypothesis suggests searching for a possible explanation of infertility among smokers who have normal seminogram.

The aim of the present work was to investigate the effect of chronic cigarette smoking on spermatozoa NRF2 gene expression and sperm DNA fragmentation in infertile men with apparently normal seminogram and if these markers could be predictors of the influence of cigarette smoking on male fertility.

\section{PATIENTS AND METHODS}

\section{Subjects:}

The study was carried out according to the principles of the Declaration of Helsinki, and the procedures were approved by the local ethics committee. Ethical approval for this study (Institutional Review Board $N^{\circ} \mathrm{R} / 16.01 .06$ ) was provided by the Institutional Review Board (IRB) for Faculty of Medicine, Mansoura University, Mansoura, Egypt on 7 January 2016.

Written informed consent was provided by all subjects. The study included 170 participants, 105 smokers (25 fertile, 80 infertile) and 65 nonsmokers (40 fertile and 25 infertile). According to Fariello et al. ${ }^{[10]}$ the infertile smokers were categorized into two subgroups; mild/ moderate smokers (smoking of 1-19 cigarettes per day, $n$ $=40$ ) heavy smokers (smoking of 20 or more cigarettes per day, $n=40)$. Fertile nonsmokers $(n=40)$ were used as standard control group while infertile nonsmokers $(n=25)$ were used as a negative control group and fertile smokers $(n=25)$ were used as a positive control group for discriminating the possible proposed effect of cigarette smoking on male fertility.

All subjects were with normal seminogram according to World Health Organization (WHO) ${ }^{[11]}$. Infertile patients attended the Andrology Clinic of Mansoura University Hospital from March 2014 to May 2015 were verified. They were married for $\geq 1$ year with failure to conceive despite unprotected regular intercourse and their female partners were normal by physical and laboratory investigations.
The fertile subjects were those of proven fertility whose wives achieved at least one full term pregnancy and the fertile nonsmokers have no history of smoking.

A detailed infertility sheet was reviewed during the physical examination including information on occupation, exposure to gonadotoxins, smoking habits (e.g. number of cigarettes smoked per day, duration of smoking in years, brand of cigarettes, and if others smoked in the house) as well as caffeine or alcohol consumption. Complete general and local genital examinations were done. The selected subjects had normal levels of serum growth hormone, $\mathrm{LH}, \mathrm{FSH}$, total and free testosterone, prolactin, estradiol and thyroid hormones. A scrotal Doppler ultrasound was performed to confirm clinically detected varicocele or to exclude subclinical one.

The exclusion criteria included any subject with abnormal semen parameter including leukocytospermia $\left(>1 \times 10^{6} / \mathrm{ml}\right)$ and those subjected to any risk factor for infertility e.g. occupational chemicals or excessive heat exposure. Also, subjects exposed to gonadotoxins e.g. pesticides or alcohol consumption, fever in the past 6 months, injury to the testes and urogenital surgery were excluded. Included smokers were only cigarette users with no history of smoking of other types e.g. marijuana. Subjects with evidence of urogenital infections; or signs of hypogonadism, small sized testes, cryptorchidism, and varicocele were excluded. Any patient with chronic illness or with a history of long-term medication e.g. corticosteroids or antioxidants were excluded.

\section{Sampling:}

After an abstinence period of $3-5$ days, semen samples were collected from all subjects by masturbation and transferred to the Medical Biochemistry Department laboratory at Mansoura Faculty of Medicine. Then, the samples were allowed to liquefy in an incubator at $37^{\circ} \mathrm{C}$ for $15 \mathrm{~min}$

\section{Semen Analysis:}

After liquefaction, ejaculate volume was recorded while sperm count and both progressive and total motility were assessed using the Motility/Concentration model of the computer assisted semen analysis (CASA software, Mira 9000 sperm Analyzer). Tri-noculer Microscope with plain objective lens (Olympus) equipped with phase contrast optics and a heated stage $\left(37^{\circ} \mathrm{C}\right)$ was used for analysis. Sperm morphology was assessed by sperm Mac stain (Fertipro, Belgium) and phase contrast microscope as outlined by $\mathrm{WHO}^{[11]}$. White blood cells (WBCs) concentration in semen was determined using the peroxidase 
staining technique described by Politch et al. ${ }^{[12]}$ Viability was assessed using Eosin Y stain, 100 cells were scored for stain exclusion (living cells) or uptake (dead cells). The criteria for normozoospermia were: semen volume $\geq 1.5 \mathrm{ml}$, sperm concentration $\geq 15 \times 10^{6} / \mathrm{ml}$, normal morphology with oval-shaped head as well as no tail irregularities in at least $4 \%$ of the spermatozoa, and sperms of progressive rapid motility $\geq 32 \%$ of spermatozoa $^{[11]}$

Seminal plasma was obtained by centrifugation at 6000 rpm and the supernatant fluid was divided into aliquots and stored at $-20^{\circ} \mathrm{C}$. It was used for the estimation of seminal plasma 8-hydroxy-2'-deoxyguanosine (8-OHdG), malondialdehyde (MDA) and total antioxidant capacity (TAC).

\section{NRF2 gene expression:}

\section{- Total RNA extraction:}

After complete liquefaction, the cells in one $\mathrm{ml}$ of every sample were pelleted by centrifugation $(6000 \mathrm{rpm}$, 10 minutes at $\left.4^{\circ} \mathrm{C}\right)$. Cellular total RNA was isolated by the RNeasy Plus Micro Kit (cat. 74134, Qiagen, Germany) according to the manufacturer's instructions. The purity and concentration of isolated RNA were determined using the NanoDrop 2000 Spectrophotometer (Thermo Scientific, USA).

\section{- Real time RT-qPCR:}

Real time reverse transcription quantitative polymerase chain reaction (RT-qPCR) was carried out according to the method of Freeman et al..$^{[13]}$ The reverse transcription reaction was done using Maxima First Strand cDNA Synthesis Kit (Thermo Scientific, USA, cat \#K1641). The synthesized cDNA was stored at $-20^{\circ} \mathrm{C}$ until used.

The real-time PCR assays were performed on the Applied Biosystems 7500, real-time PCR detection system (Life Technology, USA), using Applied Biosystems SYBR ${ }^{\circledR}$ Green PCR Master Mix (2X) (cat. 4344463). $\beta$-actin was used as a reference gene to normalize the quantity of specific mRNA. Genespecific primers for both $\beta$ - actin and NRF2 genes were designed using Primer3 software; for NRF2, sense primer: 5'-GAGAGCCCAGTCTTCAT TGC-3', antisense primer 5'-TTGGCTTCTG GACTTGGAAC-3' and for $\beta$ - actin, sense primer: 5'-GTGGCCGAGGACTTTGATTG-3' and antisense primer: 5'-GTGGGGTGGCT TTTAGG ATG$3^{\prime}$. They were purchased from Oligo ${ }^{\mathrm{TM}}$ Macrogen (Lab. Technology).
RT-qPCR reactions were done in a $25 \mu$ total reaction volume containing $12.5 \mu \mathrm{l} \mathrm{SYBR}{ }^{\circledR}$ Green PCR Master Mix reaction buffer, $2 \mu \mathrm{l}$ cDNA and forward as well as reverse gene specific primers $(10 \mathrm{pmol})$. The real-time PCR consisted of enzyme activation at $95^{\circ} \mathrm{C}$ for 10 minutes, then 40 cycles of a two-step cycling, including template denaturation at $95^{\circ} \mathrm{C}$ (15 seconds), then annealing/ extension at $60^{\circ} \mathrm{C}$ ( 1 minute). The PCR products were 203 $b p$ for NRF2 and $104 \mathrm{bp}$ for $\beta$-actin.

To check for the specificity of the RT-qPCR products, melting curve analysis was performed using the Applied Biosystems real-time PCR system software. Relative quantification of mRNA expression was calculated using the comparative threshold method $(\Delta \Delta \mathrm{Ct})$. All data were presented as the relative quantity (RQ) of NRF2 mRNA normalized with respect to the reference gene $\beta$-actin mRNA and relative to the caliberator (fertile nonsmokers) sample.

\section{DNA Fragmentation Analysis:}

DNA Fragmentation Analysis was done by agarose gel electrophoresis ${ }^{[14]}$ using Enhanced Apoptotic DNA Ladder Detection kit (BioVision Research Products, Mountain View, CA 94043.USA). Sperm pellet was washed with phosphate buffered saline and centrifuged for 5 minutes at $6000 \mathrm{rpm}$. Lysis of the cells was done with $35 \mu \mathrm{l}$ Tris EDTA lysis buffer, then $5 \mu$ of enzyme A were added and kept for 10 minutes at $37^{\circ} \mathrm{C} .5 \mu$ of enzyme B were added and incubated for 30 minutes at $50^{\circ} \mathrm{C}$. DNA was precipitated by adding $50 \mu \mathrm{l}$ of isopropanol then washed with $0.5 \mathrm{ml} \mathrm{70 \%} \mathrm{ethanol.} \mathrm{Each} \mathrm{DNA} \mathrm{pellet} \mathrm{was} \mathrm{dissolved}$ in $20 \mu \mathrm{l}$ DNA suspension buffer, electrophoresed onto a $1.8 \%$ agarose gel and stained by gel staining buffer. DNA ladder was visualized via UV Transilluminator (TUV20, OWI Scientific, France) then photographed. \% DNA fragmentation was calculated within each group (number of fragmented DNA samples / total number of samples in the group $\mathrm{x} 100)$.

\section{Measurement of seminal plasma 8-OHdG:}

Quantitative determination of the seminal plasma 8-OHdG level was performed by Abnova 8-OHdG competitive ELISA kit; (cat. KA0444) according to the manufacturer's instructions. Each sample absorbance was determined using Tecan, Sunrise Absorbance plate ELISA reader (Austria) at a wavelength of $450 \mathrm{~nm}$. The calibration curve was generated by plotting the absorbance versus log of concentration and the concentration of $8-\mathrm{OHdG}$ in each sample was obtained from the calibration curve. 


\section{Assay of oxidative stress markers:}

Malondialdehyde (MDA) was measured according to the method of Draper et al. ${ }^{[15]}$. Total antioxidant capacity (TAC) of seminal plasma was measured by using the commercially available kit (Cyman Chemical, Ann Arbor. MI, USA) ${ }^{[16]}$.

\section{Statistical Analysis:}

The data were processed and analyzed through MedCalc version 9.3. Data were expressed as mean \pm standard deviation (Mean $\pm \mathrm{SD}$ ). One way analysis of variance (ANOVA) and the two-tailed Student's t-test were used to compare results. Correlation between different variables was studied using the Pearson correlation coefficient. Receiver Operating Characteristic (ROC) curve analysis was used for determining the sensitivity and specificity of NRF2 gene expression and 8-OHdG levels as possible predictors for the adverse effects of chronic cigarette smoking on male fertility. Significance was considered when $p \leq 0.05$.

\section{RESULTS}

All subjects were age matched (mean \pm SD was 32.4 \pm 10.3 years for non-smokers, $31.9 \pm 12.3$ years for fertile smokers, $34.4 \pm 11.7$ years for infertile smokers). The semen parameters, seminal plasma $8-\mathrm{OHdG}$ and oxidative stress markers (MDA, TAC), NRF2 gene expression and DNA fragmentation data of all groups are presented in Table 1. Despite of being within normal range, semen parameters were significantly different, and all semen parameters of the infertile smokers groups showed a statistically significant decrease $(p<0.001)$.

There was a significant increase in the percentage of DNA fragmentation, seminal plasma $8 \mathrm{OHdG}$ and
MDA concentration in addition to a significant decrease in spermatozoa NRF2 gene expression and TAC of seminal plasma when comparing the mild/moderate smokers group versus the control groups $(p<0.001)$ and when comparing heavy smokers group versus all other groups $(p<0.001)$. It was noticed that the fertile smokers (positive control) showed similar significances as regards oxidative stress markers when compared to the non smokers (standard and negative controls) (Table 1).

NRF2 gene expression was correlated negatively with MDA $(\mathrm{r}=-0.788$ and $p<0.001)$, seminal $8-\mathrm{OHdG}$ level $(\mathrm{r}=-0.810$ and $p<0.001)$ and duration of smoking $(\mathrm{r}=-0.759$ and $p<0.001)$, while significant positive correlation with seminal plasma TAC was detected $(\mathrm{r}=$ 0.551 and $p<0.001)$.

ROC curve analysis was used to assess the value of determining spermatozoa NRF2 gene expression and seminal 8-OHdG levels in the assessment of the fertility status. Spermatozoa NRF2 gene expression and the seminal 8-OHdG level showed significant sensitivity and specificity of cutoff values $\leq 0.881$ and $>24.26 \mathrm{pg} / \mathrm{ml}$, respectively $(p<0.0001)$ differentiating infertile subjects from fertile controls (Table 2). As regards predicting smoking induced oxidative DNA damage, significant sensitivity and specificity was detected of cutoff values $\leq 0.967$ for spermatozoa NRF2 gene expression and $>19.33 \mathrm{pg} / \mathrm{ml}$ for seminal $8-\mathrm{OHdG}$ level $(p<0.0001)$ predicting DNA damage in smokers in relation to nonsmokers controls (Table 2).

Moreover, significant sensitivity and specificity for spermatozoa NRF2 gene expression of cutoff values $\leq$ 0.931 and for seminal $8-\mathrm{OHdG}$ levels of cutoff values $>21.24 \mathrm{pg} / \mathrm{ml}$ was found in infertile smokers in relation to controls (Table 2). 
Table 1: Semen analysis parameters, biochemical parameters, NRF2 gene expression and DNA fragmentation of all studied groups

\begin{tabular}{|c|c|c|c|c|c|c|}
\hline \multirow[b]{2}{*}{ Variable } & \multicolumn{2}{|c|}{ Non smokers } & \multicolumn{3}{|c|}{ Smokers } & \multirow[b]{2}{*}{ ANOVA $p$ value } \\
\hline & Fertile $\mathrm{N}=40$ & $\begin{array}{l}\text { Infertile } \\
\mathrm{N}=25\end{array}$ & $\begin{array}{l}\text { Fertile } \\
\mathrm{N}=25\end{array}$ & $\begin{array}{l}\text { Infertile mild/ } \\
\text { moderate } \\
\text { smokers } \\
\mathrm{N}=40\end{array}$ & $\begin{array}{c}\text { Infertile heavy } \\
\text { smokers } \\
\mathrm{N}=40\end{array}$ & \\
\hline $\begin{array}{l}\text { Smoking Duration } \\
\text { (years) }\end{array}$ & - & - & $6.8 \pm 2.2$ & $8.15 \pm 2.05$ & $8.9 \pm 1.68$ & - \\
\hline Volume (ml) & $3.7 \pm 0.9$ & $3.2 \pm 1.1$ & $3.3 \pm 1.0$ & $3.5 \pm 0.87$ & $3.9 \pm 1.1$ & 0.18 \\
\hline $\begin{array}{l}\text { Concentration } \\
\left(10^{6} / \mathrm{ml}\right)\end{array}$ & $66.0 \pm 17.5$ & $21.5 \pm 11.8^{\dagger}$ & $63.5 \pm 23.2^{*}$ & $59.9 \pm 18.9^{\dagger *}$ & $29.9 \pm 12.3^{\dagger \S \uparrow}$ & $<0.001$ \\
\hline $\begin{array}{l}\text { Normal } \\
\text { morphology (\%) }\end{array}$ & $25.3 \pm 9.5$ & $14.8 \pm 10.8^{\dagger}$ & $31.5 \pm 14.2^{\dagger \ddagger}$ & $18.3 \pm 5.7^{\dagger+\S}$ & $6.4 \pm 2.2^{\dagger+\S \rrbracket}$ & $<0.001$ \\
\hline \% Motility (PR) & $59.8 \pm 16.3$ & $43.8 \pm 17.5^{\dagger}$ & $55.4 \pm 21.6^{\ddagger}$ & $49.8 \pm 12.7^{\dagger \star \S}$ & $39.6 \pm 14.3^{\dagger \ddagger \S \rrbracket}$ & $<0.001$ \\
\hline WBCs $\left(10^{6} / \mathrm{ml}\right)$ & $0.22 \pm 0.06$ & $0.57 \pm 0.31^{\dagger}$ & $0.32 \pm 0.11^{\dagger \star}$ & $0.24 \pm 0.06^{\ddagger \S}$ & $0.6 \pm 0.17^{\dagger \pm \S}$ & $<0.001$ \\
\hline $\operatorname{MDA}(\mu \mathrm{mol} / \mathrm{L})$ & $4.1 \pm 1.2$ & $3.94 \pm 0.70$ & $7.32 \pm 1.66^{\dagger}$ & $7.80 \pm 1.6^{\dagger}$ & $10.3 \pm 2.30^{\dagger+\S \rrbracket}$ & $<0.001$ \\
\hline $\begin{array}{l}\text { TAC (Trolox } \\
\text { equivalent) }\end{array}$ & $2.1 \pm 0.6$ & $1.97 \pm 0.44$ & $1.45 \pm 0.26^{\dagger}$ & $1.30 \pm 0.42^{\dagger \ddagger \S}$ & $0.87 \pm 0.24^{\dagger \ddagger \S \rrbracket}$ & $<0.001$ \\
\hline 8OHdG (pg/ml) & $15.03 \pm 3.8$ & $15.8 \pm 5.2$ & $21.9 \pm 8.06^{\dagger *}$ & $28.6 \pm 10.8^{\dagger \ddagger \S}$ & $38.3 \pm 10.13^{\dagger+\S}$ & $<0.001$ \\
\hline $\begin{array}{l}\text { NRF2 gene } \\
\text { expression }\end{array}$ & $1 \pm 0.01$ & $0.995 \pm 0.01$ & $0.96 \pm 0.04^{\dagger+}$ & $0.82 \pm 0.1^{\dagger \ddagger \S}$ & $0.76 \pm 0.01^{\dagger+\S \uparrow}$ & $<0.001$ \\
\hline $\begin{array}{l}\% \text { DNA } \\
\text { fragmentation }\end{array}$ & $10 \%(4 / 40)$ & $12 \%(3 / 25)$ & $16 \%(4 / 25)^{\dagger *}$ & $35 \%(14 / 40)^{\dagger+\S}$ & $52.5 \%(21 / 40)^{\dagger+\S \rrbracket}$ & $<0.001$ \\
\hline
\end{tabular}

PR progressive motility.

$p$ significance when $<0.05$, Data were presented as mean $\pm \mathrm{SD}$

$\uparrow$ Significance of infertile nonsmokers, fertile smokers, infertile mild to moderate smokers and heavy smokers groups compared to the fertile nonsmokers group.

† Significance of fertile smokers, infertile mild to moderate smokers and heavy smokers groups compared to the infertile nonsmokers group. $\S$ Significance of infertile mild to moderate smokers and heavy smokers groups compared to the fertile smokers group.

I Significance of the infertile heavy smokers group compared to mild to moderate smokers group. 
Table 2: ROC curve analysis of spermatozoa NRF2 gene expression and seminal 8-OHdG levels in studied groups.

\begin{tabular}{|c|c|c|c|c|c|c|}
\hline \multirow[t]{2}{*}{ ROC analysis } & \multicolumn{2}{|c|}{ Infertile groups } & \multicolumn{2}{|c|}{ Smokers groups } & \multicolumn{2}{|c|}{ Infertile smokers groups } \\
\hline & NRF2 & 8-OHdG & NRF2 & 8-OHdG & NRF2 & 8-OHdG \\
\hline \multirow[t]{2}{*}{$\begin{array}{l}\text { AUC } \\
(95 \% \mathrm{CI})\end{array}$} & 0.858 & 0.802 & 0.976 & 0.921 & 0.984 & 0.932 \\
\hline & $(0.796-0.907)$ & $(0.734-0.859)$ & $(0.941-0.994)$ & $(0.870-0.957)$ & $(0.952-0.997)$ & $(0.883-0.965)$ \\
\hline Cut off value & $\leq 0.881$ & $>24.26 \mathrm{pg} / \mathrm{ml}$ & $\leq 0.967$ & $>19.33 \mathrm{pg} / \mathrm{ml}$ & $\leq 0.931$ & $>21.24 \mathrm{pg} / \mathrm{ml}$ \\
\hline Sensitivity & $66.7 \%$ & $62.9 \%$ & $85.7 \%$ & $93.4 \%$ & $95 \%$ & $91.3 \%$ \\
\hline Specificity & $98.5 \%$ & $92.3 \%$ & $100 \%$ & $89.2 \%$ & $93.3 \%$ & $81.1 \%$ \\
\hline Positive PV & $98.6 \%$ & $93 \%$ & $100 \%$ & $93.3 \%$ & $92.7 \%$ & $81.1 \%$ \\
\hline Negative PV & $64.6 \%$ & $60.6 \%$ & $81.2 \%$ & $89.2 \%$ & $95.5 \%$ & $91.2 \%$ \\
\hline$p$ value & $<0.0001$ & $<0.0001$ & $<0.0001$ & $<0.0001$ & $<0.0001$ & $<0.0001$ \\
\hline
\end{tabular}

AUC, Area under curve; CI, Confidence interval; PV, Predictive value

\section{DISCUSSION}

The present study is tracking the effect of smoking on spermatozoa DNA integrity and subsequently possible mechanisms for infertility in spite of normal seminogram. Many studies have been applied to explain the molecular mechanisms of smoking induced infertility, yet the exact mechanism still not clear. Semen parameters were evaluated in infertile smokers in comparison to controls. A panel of molecular markers including spermatozoa NRF2 gene expression and oxidative DNA fragmentation markers as $8-\mathrm{OHdG}$ was investigated to explain a possible mechanism of infertility. The sensitivity and specificity of NRF2 gene expression and 8-OhdG levels were assessed to determine the possibility of being predictors of smoking induced infertility.

In the current study, the semen parameters were affected in smoking dependent manner, but the overall semen quality was within normal, a finding in accordance with the results detected by Meri et al. ${ }^{[17]}$ and $\mathrm{Yu}$ et $a{ }^{[18]}{ }^{[18}$. On the contrary, other researchers demonstrated a negative influence of smoking on human semen parameters ${ }^{[8]}$ and strong evidence supporting smoking adverse effects on several semen parameters are reported ${ }^{[19]}$.

It is thought that the correlation between smoking and infertility may be related to a cumulative effect, because the process of oxidative burden may take a time to induce the effects over the years. Another important factor is the genetic susceptibility as the genetic susceptible individuals may complain earlier than others. Moreover, the infertility may be assisted by adjuvant combined environmental toxic factors that may work by interacting mechanisms.

In the present study, spermatozoa NRF2 gene expression showed significant decrease in smokers complaining of infertility. Yu et al. ${ }^{[20]}$ reported that smoking affect semen quality by interfering with signaling pathways and also by modifying important enzymes. Generation of sperm in the testicles and their maturation in the epididymis produces large amounts of ROS then NRF2 plays a protective role against oxidative damage. Deficiencies in antioxidant capability with additional exposure to ROS will lead 
to harmful effects. Smoking switch off this important gene, but the mechanism is not well known. It is worth to say that smoking could work on the susceptible patient having NRF2 single nucleotide polymorphism ${ }^{[21]}$. It is expected that genetic variations in major antioxidant genes will alter the susceptibility of a male to infertility and defective spermatogenesis ${ }^{[22]}$. Directly, smoking can also affect NRF2 proteins and impair antioxidant induction $^{[23]}$

In the current study, there were significant increases in sperm DNA fragmentation in smokers compared to nonsmokers. It was declared that direct correlation was found between sperm DNA fragmentation and the number of smoked cigarettes as well as smoking duration $^{[24]}$. This may be caused by insufficient expression of seminal antioxidant enzymes and failure to provide full protection against DNA damage ${ }^{[25,26]}$.

The underlying mechanisms of DNA fragmentation may be complex. Cigarette smoking induces the formation of oxidative products, such as $8-\mathrm{OHdG}$, and causes DNA damage that has adverse effects on reproductive outcome ${ }^{[27]}$. $8-\mathrm{OHdG}$ is an indicator of oxidative spermatozoa DNA damage leading to accelerated testicular aging. This could be considered as a possible causative factor that leads to infertility and congenital malformation ${ }^{[26]}$. Exposure to polycyclic aromatic hydrocarbons is another important factor in the geno-toxicity by inducing DNA adducts associated with poor semen quality ${ }^{[28]}$. In addition, smoking is associated with histone-to-protamine transition abnormalities in the sperm leading to increased DNA fragmentation ${ }^{[18]}$. So, detecting DNA damage is an important diagnostic marker that is valuable for appropriate management ${ }^{[29]}$.

Not all smokers are infertile suggesting that certain genetic polymorphisms in xenobiotic metabolism genes and DNA repair may raise the susceptibility to infertility among smokers ${ }^{[4]}$. La Maestra et al. ${ }^{[30]}$ found that smoking induced oxidative stress produces cellular apoptosis as a defensive mechanism which ends in decreased the number of spermatogonia. This may explain the changes in semen quality despite they are morphologically within normal range. These effects could be the key mechanisms for proposed infertility.

The negative correlation found between the expression of NRF2 gene and MDA and seminal plasma $8-\mathrm{OHdG}$ and the positive correlation with TAC suggests a possible associating effect. These relations are considered logic as in the oxidative stress environment together with decreased antioxidant enzymes, there will be increased DNA fragmentation and lipid intoxication leading to increased MDA.
The value of spermatozoa NRF2 expression and 8 -OHdG levels in predicting smoking as a possible cause of infertility in male with apparently normal seminogram was assessed. Smoking induced infertility could be strongly predicted when spermatozoa NRF2 expression levels $\leq 0.931$ and $8-\mathrm{OHdG}>21.24 \mathrm{pg} /$ $\mathrm{ml}$ (Table 2). Moreover, NRF2 expression and seminal 8-OHdG assay could be used for predicting the detrimental effect of smoking on spermatozoa functions with significant positive and negative predictive values (Table 2).

\section{CONCLUSION}

Chronic cigarette smoking may be a hidden causative mechanism for male infertility through affecting spermatozoa functions. This might occur by DNA fragmentation secondary to spermatozoa oxidative stress as a result of inhibited spermatozoa NRF2 gene expression. The presence of normal seminal parameters could not exclude the potential effect of chronic smoking in infertility; even it is dependent on the rate and duration of smoking. NRF2 gene expression and seminal 8-OHdG levels might serve as potential predictors of smoking induced infertility with high sensitivity and specificity. The discovery and validation of smoking induced oxidative stress markers among infertile smokers may facilitate the improvement of clinical approaches.

\section{ABBREVIATIONS:}

8-OHdG (8-hydroxy-2'-deoxyguanosine), MDA (Malondialdehyde), NRF2 (Nuclear factor-erythroid 2-related factor 2), ARE (Antioxidant response element), TAC (Total antioxidant capacity), ROS (Reactive oxygen species), ROC (Receiver operating characteristic), RT-qPCR (Reverse transcription quantitative polymerase chain reaction), WHO (World Health Organization).

\section{CONFLICTS OF INTEREST:}

There are no conflicts of interest.

\section{REFERENCES:}

1. Thoma ME, McLain AC, Louis JF, et al. Prevalence of infertility in the United States as estimated by the current duration approach and a traditional constructed approach. Fertil Steril. 2013; 99(5):1324-1331. e1321.

2. Kovac JR, Pastuszak AW, Lamb DJ. The use of genomics, proteomics, and metabolomics in identifying biomarkers of male infertility. Fertil Steril. 2013; 99(4):998-998. 
3. Yeni E, Ciftci H, Savas M, Verit A, Taskin A. Is oxidative stress an etiologic factor in idiopathic male infertility? Turk J Med Sci. 2010; 40(1): 1-6.

4. Harlev A, Agarwal A, Gunes SO, Shetty A, du Plessis SS. Smoking and Male Infertility: An Evidence-Based Review. World J Mens Health. 2015; 33(3):14360-. doi: 10.5534/wjmh.2015.33.3.143.

5. Practice Committee of American society for reproductive medicine. Smoking and infertility. Fertil Steril. 2008; 90 (5Suppl.): S254-9. doi: 10.1016/j. fertnstert.2008.08.035.

6. Kensler TW, Wakabayashi N, Biswal S. Cell survival responses to environmental stresses via the Keap1Nrf2-ARE pathway. Annu Rev Pharmacol Toxicol. 2007; 47: 89116-

7. Nakamura BN, Lawson G, Chan JY, Banuelos J, Cortes MM, Hoang YD et al. Knockout of the transcription factor NRF2 disrupts spermatogenesis in an agedependent manner. Free Radic Biol Med. 2010; 49(9): 1368- 79. doi: 10.1016/j.freeradbiomed.2010.07.019.

8. 8. Mostafa T. Cigarette smoking and male infertility. J Adv Res. 2010; 1(3): 179-86.

9. 9. Belcheva A, Ivanova-Kicheva $M$, Tzvetkova $P$, Marinov M. Effects of cigarette smoking on sperm plasma membrane integrity and DNA fragmentation. Int J Androl. 2004; 27(5):296-300.

10. Fariello RM, Pariz JR, Spaine DM, Gozzo FC, Pilau EJ, Fraietta R et al. Effect of smoking on the functional aspects of sperm and seminal plasma protein profiles in patients with varicocele. Hum. Reprod. 2012; 27(11): 3140-9. doi: 10.1093/humrep/des287.

11. WHO (World Health Organization). WHO laboratory manual for the examination and processing of human semen, 2010; $5^{\text {th }}$ Ed.

12. Politch JA, Tucker L, Bowman FP, Anderson DJ. Concentrations and significance of cytokines and other immunologic factors in semen of healthy fertile men. Hum Reprod. 2007; 22:2928-35.

13. Freeman W M, Walker S J and Vrana K E: Quantitative RT-PCR: pitfalls and potential. Biotechniques. 1999; 26:112 -122, 124- 125.

14. Daniel PT, Sturm I, Ritschel S, Friedrich K, Do“rken $\mathrm{B}$, Bendzko $\mathrm{P}$ et al. Detection of genomic DNA fragmentation during apoptosis (DNA Ladder) and the simultaneous isolation of RNA from Low Cell numbers. Anal Biochem. 1999; 266 (1): 110-5.
15. Draper HH, Squires EJ, Mahmoodi H, Wu J, Agarwal S, Hadley M. A comparative evaluation of thiobarbituric acid methods for the determination of malondialdehyde in biological materials. Free Radic Biol Med. 1993; 15(4): 353- 63.

16. Rice-Evans C, Miller NJ. Total antioxidant status in plasma and body fluids. Methods Enzymol. 1994; 234: $279-93$.

17. Meri ZB, Irshid IB, Migdadi M, Irshid AB, Mhanna SA. Does cigarette smoking affect seminal fluid parameters? A comparative study. Oman Med J. 2013; 28(1): 12- 5. doi: 10.5001/omj.2013.03.

18. Yu B, Qi Y, Liu D, Gao X, Chen H, Bai C et al. Cigarette smoking is associated with abnormal histone-to-protamine transition in human sperm. Fertil Steril. 2014; 101(1): 51-7. doi: 10.1016/j. fertnstert.2013.09.001.

19. Kovac JR, Khanna A, Lipshultz LI. The effects of cigarette smoking on male fertility. Postgrad Med. 2015; 127(3):338- 41. doi: 10.1080/ 00325481.2015 .1015928 .

20. Yu B, Chen J, Liu D, Zhou H, Xiao W, Xia X et al. Cigarette smoking is associated with human semen quality in synergy with functional NRF2 polymorphisms. Biol Reprod. 2013; 89(1):5. doi: 10.1095/biolreprod.113.109389.

21. Yu B, Huang Z. Variations in Antioxidant Genes and Male Infertility. Biomed Res Int. 2015; 2015:513196. doi: $10.1155 / 2015 / 513196$.

22. Yarosh SL, Kokhtenko EV, Churnosov MI, Solodilova MA, Polonikov AV. Joint effect of glutathione S-transferase genotypes and cigarette smoking on idiopathic male infertility. Andrologia. 2015; 47:980-986.

23. Malhotra D, Thimmulappa R, Navas-Acien A, Sandford A, Elliott M, Singh A et al. Decline in NRF2-regulated antioxidants in chronic obstructive pulmonary disease lungs due to loss of its positive regulator, DJ-1. Am J Respir Crit Care Med. 2008; 178(6): 592- 604. doi: 10.1164/rccm.200803380-OC.

24. Taha EA, Ez-Aldin AM, Sayed SK, Ghandour NM, Mostafa T. Effect of Smoking on Sperm Vitality, DNA Integrity, Seminal Oxidative Stress, Zinc in Fertile men. Urology. 2012; 80(4): 822-5. doi: 10.1016/j. urology.2012.07.002.

25. Linschooten JO, Laubenthal J, Cemeli E, Baumgartner A, Anderson D, Sipinen VE et al. Incomplete 
protection of genetic integrity of mature spermatozoa against oxidative stress. Reprod Toxicol. 2011 Jul; 32 (1): 10611-. doi: 10.1016/j.reprotox.2011.05.004.

26. Mishra S, Kranthi V, Kumar R, Malhotra N, Mohanty $\mathrm{K}$, Pathak V et al. Oxidative Damage to Sperm DNA: Clinical Implications. Andrology. 2014; 3 (1): 116. doi:10.4172/ $2167-0250.1000116$.

27. Meseguer M, Martínez-Conejero JA, O'Connor JE, Pellicer A, Remohí J, Garrido N. The significance of sperm DNA oxidation in embryo development and reproductive outcome in an oocyte donation program: a new model to study a male infertility prognostic factor. Fertil Steril. 2008; 89(5):1191-9.

28. Jurewicz J, Radwan M, Sobala W, Brzeźnicki S, Ligocka D, Radwan $\mathrm{P}$ et al. Association between a biomarker of exposure to polycyclic aromatic hydrocarbons and semen quality. Int J Occup Med Environ Health. 2013; 26(5):790801-. doi: 10.2478/ s13382- 013- 0152-.9.

29. Kumar K, Deka D, Singh A, Mitra DK, Vanitha BR, Dada R. Predictive value of DNA integrity analysis in idiopathic recurrent pregnancy loss following spontaneous conception. J Assist Reprod Genet. 2012; 29: 86167-. doi: 10.1007/s10815 -012 -9801- 3.

30. La Maestra S, De Flora S, Micale RT. Effect of cigarette smoke on DNA damage, oxidative stress, and morphological alterations in mouse testis and spermatozoa. Int J Hyg Environ Health. 2015; 218:117-122. 